\title{
Identification of Halohydrins as Potential Disinfection By-Products in Treated Drinking Water
}

\author{
Karl J. Jobst, ${ }^{1}$ Vince Y. Taguchi, ${ }^{2}$ Richard D. Bowen, ${ }^{3}$ \\ Moschoula A. Trikoupis, ${ }^{4}$ and Johan K. Terlouw ${ }^{1}$ \\ ${ }^{1}$ Department of Chemistry and Chemical Biology, McMaster University, 1280 Main Street West, Hamilton, ON, Canada L8S $4 M 1$ \\ ${ }^{2}$ Laboratory Services Branch, Ministry of the Environment (MOE), 125 Resources Road, Toronto, ON, Canada M9P 3V6 \\ ${ }^{3}$ School of Life Sciences, University of Bradford, Richmond Road, Bradford BD7 1DP, UK \\ ${ }^{4}$ Environmental Innovations Branch, Ministry of the Enviroment 135 Street Clair Avenue West, 11th Floor, \\ Toronto, ON, Canada M4V $1 P 5$
}

Correspondence should be addressed to Johan K. Terlouw, terlouwj@mcmaster.ca

Received 15 June 2011; Accepted 15 August 2011

Academic Editor: Edenir R. Pereira-Filho

Copyright (c) 2011 Karl J. Jobst et al. This is an open access article distributed under the Creative Commons Attribution License, which permits unrestricted use, distribution, and reproduction in any medium, provided the original work is properly cited.

In 2001, two potential disinfection by-products (DBPs) were tentatively identified as 1-aminoxy-1-chlorobutan-2-ol (DBP-A) and its bromo analogue (DBP-B) (Taguchi 2001). Subsequently it became clear, by consulting an updated version of the NIST database, that their mass spectra are close to those of the halohydrins 4-chloro-2-methylbutan-2-ol and 3-bromo-2-methylbutan-2-ol. To establish the structures of these DBPs, additional mass spectrometric experiments, including Fourier transform ion cyclotron resonance (FTICR), were performed on treated drinking water samples and authentic halohydrin standards. It appears that DBPA is 3-chloro-2-methylbutan-2-ol and that DBP-B is its bromo analogue. DBP-B has been detected in ozonated waters containing bromide. Our study also shows that these DBPs can be laboratory artefacts, generated by the reaction of residual chlorine in the sample with 2-methyl-2-butene, the stabilizer in the $\mathrm{CH}_{2} \mathrm{Cl}_{2}$ used for extraction. This was shown by experiments using $\mathrm{CH}_{2} \mathrm{Cl}_{2}$ stabilized with deuterium labelled 2-methyl-2-butene. Quenching any residual chlorine in the drinking water sample with sodium thiosulfate minimizes the formation of these artefacts.

\section{Introduction}

Since its inception in the late 19th century, drinking water disinfection has been one of the most important advancements for public health. While disinfectants such as chlorine, ozone, chloramines, and chlorine dioxide are used to kill harmful microorganisms, an unintended consequence is the formation of the so-called disinfection by-products (DBPs), which arise from the degradation of natural organic matter by the disinfectants $[1,2]$. It is now widely known that DBPs, such as the two most common classes of DBPs, the trihalomethanes (THMs) and the haloacetic acids (HAAs), are associated with long-term health risks $[3,4]$.

The Ontario Ministry of the Environment (MOE) has been monitoring raw and treated drinking water as part of the Drinking Water Surveillance Program (DWSP) since 1986. Target compound analyses include THMs and HAAs.
To complement these target compound analyses, gas chromatography-mass spectrometry (GC-MS) is routinely used to characterize a broad range of organic compounds, including DBPs, which may also be present in drinking water but whose identity has not yet been established.

More than ten years ago, two unexpected disinfection byproducts, a chloro compound labelled DBP-A, and a bromo analogue DBP-B, were being detected. Their electron ionization (EI) mass spectra were not available in the NIST98 database. On the basis of various mass spectrometric experiments [5], DBP-A and DBP-B were tentatively identified as the halogenated aminoxyalcohols of Scheme 1 . However, the dearth of information [6] available on the dissociation characteristics of ionized aminoxyalcohols made such a proposal rather speculative, especially since the proposed structures would not be expected to be stable. This prompted our subsequent experimental and computational studies $[7,8]$ of 


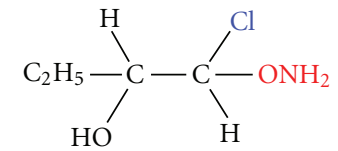

1-Aminoxy-1-chlorobutan-2-ol

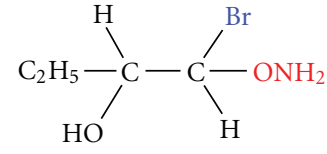

1-Aminoxy-1-bromobutan-2-ol
Scheme 1: Tentative structure proposals from [5] for DBP-A and DBP-B.

the dissociation characteristics of ionized 2-aminoxyethanol and its hydroxyamino isomer, $\mathrm{HOCH}_{2} \mathrm{CH}_{2} \mathrm{ONH}_{2}$ and $\mathrm{HOCH}_{2} \mathrm{CH}_{2} \mathrm{NHOH}$, respectively.

Following the study of [5], the updated NIST02 database was released. This version of the database included the EI mass spectra of the halohydrins 4-chloro-2-methylbutan2-ol and 3-bromo-2-methylbutan-2-ol shown in Scheme 2. The spectrum of the chloro compound appeared to be very close to that of DBP-A, while that of DBP-B could be that of 3-bromo-2-methylbutan-2-ol-a bromohydrin detected in ozonated waters as reported in $[9,10]$.

A major challenge associated with the interpretation of the EI mass spectra of DBP-A and DBP-B is that the spectra do not display a molecular ion. In the study of [5], complementary chemical ionization (CI) experiments, using $\mathrm{NH}_{3}$ as the reagent gas, yielded peaks at $\mathrm{m} / \mathrm{z} 140$ and $\mathrm{m} / \mathrm{z} 184$ for DBP-A and DBP-B, respectively. These were assigned to the formation of protonated molecules $\left[\mathrm{M}+\mathrm{H}^{+}\right]$. This seems to be at odds with the presence of the above halohydrins, whose $\left[\mathrm{M}+\mathrm{H}^{+}\right]$ions correspond with peaks at $\mathrm{m} / \mathrm{z} 123$ and $\mathrm{m} / \mathrm{z}$ 167 , respectively.

In this study, we aimed to determine whether the above DBPs have an "aminoxy" or a "halohydrin" structure by performing additional GC-MS experiments on treated water samples and by analyzing authentic samples of the halohydrins prepared via unambiguous synthetic procedures based upon the early study of [11].

\section{Experimental}

Each $800 \mathrm{~mL}$ aliquot of water was spiked with the internal standard, $\mathrm{d}_{10}$-phenanthrene, and the surrogates, $\mathrm{d}_{6}-N$-nitrosodimethylamine (NDMA) and $\mathrm{d}_{3}-2,4$-dichlorophenol, used to monitor recoveries. The $\mathrm{pH}$ was adjusted to approximately 12 with $\mathrm{NaOH}$ solution, and the sample was serially extracted with $\mathrm{CH}_{2} \mathrm{Cl}_{2}$. HPLC-grade $\mathrm{CH}_{2} \mathrm{Cl}_{2}$ was supplied by Caledon Laboratories (Georgetown, ON, Canada). According to the manufacturer's specification, this solvent is stabilized with $\sim 50 \mathrm{ppm}$ of 2-methyl-2-butene (amylene). The $\mathrm{pH}$ of the aqueous phase was adjusted to approximately 2 with $\mathrm{H}_{2} \mathrm{SO}_{4}$, and the acidified water was serially extracted with $\mathrm{CH}_{2} \mathrm{Cl}_{2}$. Both sets of extracts were combined, dried over $\mathrm{Na}_{2} \mathrm{SO}_{4}$, concentrated, transferred to a $2 \mathrm{~mL}$ autosampler vial, and concentrated again to approximately $200 \mu \mathrm{L}$ for GC-MS analysis.

The EI and CI GC-MS analysis of the water samples was performed using an Agilent 6890 Series GC coupled to a Micromass GCT Time-of-Flight Mass Spectrometer at McMaster University. For the CI experiments, ammonia was used as the reagent gas. Selected EI experiments were also

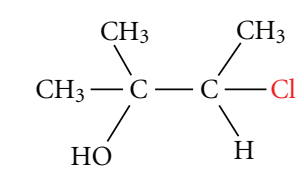

3-Chloro-2-methylbutan-2-ol<smiles>CC(Br)C(C)(C)O</smiles>

3-Bromo-2-methylbutan-2-ol

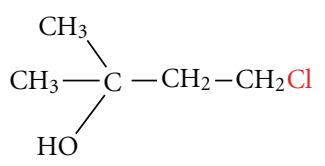

4-Chloro-2-methylbutan-2-ol
Scheme 2: The halohydrins of this study.

performed using a Hewlett Packard (HP) 6890 GC coupled to an HP 5973 mass selective detector (MSD) at the Ontario Ministry of the Environment (MOE). The column was a $60 \mathrm{~m}$ Restek Rtx-5, $0.25 \mathrm{~mm}$ i.d., $0.25 \mu \mathrm{m}$ film thickness. The temperature program was as follows: $35^{\circ} \mathrm{C}$; held for 1 minute; then increased to $320^{\circ} \mathrm{C}$ at a rate of $10^{\circ} \mathrm{C} / \mathrm{min}$. The ion source and transfer line temperatures were $230^{\circ} \mathrm{C}$ and $320^{\circ} \mathrm{C}$, respectively. Splitless injection was used for all experiments.

Authentic samples of the halohydrins 3- and 4-chloro-2methylbutan-2-ol, 3- and 4-bromo-2-methylbutan-2-ol, and 1-chloro-2-methylbutan-2-ol were analyzed on the above instruments and also on the Varian 920FT GC-FTICR mass spectrometer at the MOE and the McMaster University ZAB$\mathrm{R}$ instrument [12].

The halohydrins [11] 3- and 4-chloro-2-methylbutan-2-ol and 3- and 4-bromo-2-methylbutan-2-ol were obtained from 3-chlorobutan-2-one, methyl 3-chloropropionate, methyl 2-bromopropionate, and methyl 3-bromopropionate (or the corresponding acid chlorides) by Grignard reactions with methylmagnesium iodide. The labelled chlorohydrin $\left(\mathrm{CD}_{3}\right)_{2} \mathrm{C}(\mathrm{OH}) \mathrm{CHClCH}_{3}$ was analogously obtained using $\mathrm{CD}_{3} \mathrm{MgI}$. 1-chloro-2-methylbutan-2-ol was prepared by addition of chloroacetone to ethylmagnesium bromide. The labelled 2-methyl-2-butene $\left(\mathrm{CD}_{3}\right)_{2} \mathrm{C}=\mathrm{CHCH}_{3}$ was prepared by dehydration of the labelled 2-methylbutan-2-ol $\left(\mathrm{CD}_{3}\right)_{2} \mathrm{C}(\mathrm{OH}) \mathrm{CH}_{2} \mathrm{CH}_{3}$ with $\mathrm{H}_{2} \mathrm{SO}_{4}$ [13]. $\left(\mathrm{CD}_{3}\right)_{2} \mathrm{C}(\mathrm{OH}) \mathrm{CH}_{2} \mathrm{CH}_{3}$ was obtained from $\mathrm{d}_{6}$-acetone by a Grignard reaction with $\mathrm{C}_{2} \mathrm{H}_{5} \mathrm{MgBr}$.

In general, the Grignard reactions were performed by adding an ethereal solution of the ketone or ester to a solution of the relevant alkylmagnesium halide under a nitrogen atmosphere at such a rate as to induce gentle reflux. After stirring overnight, sufficient saturated aqueous ammonium chloride $(150 \mathrm{~mL} / \mathrm{mol}$ of alkylmagnesium halide) was added dropwise to cause a clear solution to develop. The resultant solution was decanted, and the residual organic solids were extracted with diethyl ether $(200 \mathrm{~mL} / \mathrm{mol}$ alkylmagnesium halide). The combined organic ethereal solution was dried with $\mathrm{MgSO}_{4}$ and then evaporated at reduced pressure to give the crude halohydrin as an amber oil. The halohydrins were purified by distillation at reduced pressure $(\sim 35 \mathrm{mmHg})$. 
TABLE 1: Accurate mass measurements (EI mode) of the DBPs using GCT and FTICR instruments.

\begin{tabular}{|c|c|c|c|c|c|c|}
\hline DBP & Formula & Mass (Calc.) & Mass $(\mathrm{GCT})^{[\mathrm{a}]}$ & $\operatorname{Dev}_{.}^{[c]}$ & Mass (FTICR) ${ }^{[\mathrm{b}]}$ & $\operatorname{Dev}^{[c]}$ \\
\hline \multirow{7}{*}{ A } & $\mathrm{C}_{2} \mathrm{H}_{3} \mathrm{O}$ & 43.01784 & 43.01795 & 2.6 & - & - \\
\hline & $\mathrm{C}_{3} \mathrm{H}_{7} \mathrm{O}$ & 59.04914 & 59.04895 & -3.2 & - & - \\
\hline & $\mathrm{C}_{5} \mathrm{H}_{9}$ & 69.06988 & 69.07005 & 2.5 & 69.06977 & -1.5 \\
\hline & $\mathrm{C}_{4} \mathrm{H}_{7} \mathrm{O}$ & 71.04914 & 71.04915 & 0.1 & 71.04912 & -0.3 \\
\hline & $\mathrm{C}_{5} \mathrm{H}_{11} \mathrm{O}$ & 87.08044 & 87.08015 & -3.3 & - & - \\
\hline & $\mathrm{C}_{4} \mathrm{H}_{8} \mathrm{O}^{35} \mathrm{Cl}$ & 107.02582 & 107.02595 & 1.2 & 107.02577 & -0.5 \\
\hline & $\mathrm{C}_{4} \mathrm{H}_{8} \mathrm{O}^{37} \mathrm{Cl}$ & 109.02287 & 109.02305 & 1.7 & 109.02290 & 0.3 \\
\hline \multirow{8}{*}{ B } & $\mathrm{C}_{2} \mathrm{H}_{3} \mathrm{O}$ & 43.01784 & 43.01815 & 7.2 & - & - \\
\hline & $\mathrm{C}_{2} \mathrm{H}_{5} \mathrm{O}$ & 45.03349 & 45.03405 & 12.4 & - & - \\
\hline & $\mathrm{C}_{3} \mathrm{H}_{7} \mathrm{O}$ & 59.04914 & 59.04925 & 1.9 & - & - \\
\hline & $\mathrm{C}_{5} \mathrm{H}_{9}$ & 69.06988 & 69.06985 & -0.4 & 69.06985 & -0.4 \\
\hline & $\mathrm{C}_{4} \mathrm{H}_{7} \mathrm{O}$ & 71.04914 & 71.04945 & 4.4 & 71.04921 & 1.0 \\
\hline & $\mathrm{C}_{5} \mathrm{H}_{11} \mathrm{O}$ & 87.08044 & 87.08085 & 4.7 & - & - \\
\hline & $\mathrm{C}_{4} \mathrm{H}_{8} \mathrm{O}^{79} \mathrm{Br}$ & 150.97530 & 150.97695 & 10.9 & 150.97542 & 0.7 \\
\hline & $\mathrm{C}_{4} \mathrm{H}_{8} \mathrm{O}^{81} \mathrm{Br}$ & 152.97326 & 152.97375 & 3.2 & 152.97340 & 0.9 \\
\hline \multirow{8}{*}{$\mathrm{C}$} & $\mathrm{C}_{2} \mathrm{H}_{3} \mathrm{O}$ & 43.01784 & 43.01815 & 7.2 & - & - \\
\hline & $\mathrm{C}_{2} \mathrm{H}_{5} \mathrm{O}$ & 45.03349 & 45.03385 & 8.0 & - & - \\
\hline & $\mathrm{C}_{4} \mathrm{H}_{7}$ & 55.05423 & 55.05455 & 5.8 & - & - \\
\hline & $\mathrm{C}_{3} \mathrm{H}_{5} \mathrm{O}$ & 57.03349 & 57.03395 & 8.1 & - & - \\
\hline & $\mathrm{C}_{4} \mathrm{H}_{9} \mathrm{O}$ & 73.06479 & 73.06455 & -3.3 & 73.06467 & -1.6 \\
\hline & $\mathrm{C}_{3} \mathrm{H}_{6} \mathrm{O}^{35} \mathrm{Cl}$ & 93.01017 & 93.01035 & 1.9 & 93.01013 & -0.4 \\
\hline & $\mathrm{C}_{4} \mathrm{H}_{8} \mathrm{O}^{35} \mathrm{Cl}$ & 107.02582 & 107.02645 & 5.9 & 107.02572 & -1.0 \\
\hline & $\mathrm{C}_{4} \mathrm{H}_{8} \mathrm{O}^{37} \mathrm{Cl}$ & 109.02287 & 109.02355 & 6.2 & 109.02279 & -0.7 \\
\hline
\end{tabular}

Note. Measurements obtained using ${ }^{[a]}$ treated drinking water samples; ${ }^{[\mathrm{b}]}$ authentic standards of the halohydrins; the ion-guide of the FT-ICR instrument only permits ions with $\mathrm{m} / \mathrm{z}>65$ to be transmitted to the cell; ${ }^{[c]}$ the deviation from the calculated value is given in parts per million.

${ }^{1} \mathrm{H}$ NMR indicated that the above materials were essentially pure.

\section{Results and Discussion}

3.1. Identification of the Disinfection By-Products DBP-A, $D B P-B$, and DBP-C. The total ion chromatogram (TIC) of the treated drinking water sample (Figure 1) shows the disinfection byproduct peak DBP-A eluting at a retention time of 8.03 minutes. Its bromo analogue (DBP-B), along with several other halogenated species (DBP-C to DBP-H), is also present at levels ranging from ca. $10-100 \mathrm{ppb}$. In this study, we will focus on the structure analysis of DBPs A, B, and C.

The EI mass spectrum of (DBP-A) see Figure 2(a), resembles that of 4-chloro-2-methylbutan-2-ol from the NIST02 database. Nevertheless, the aminoxy compound of Scheme 1 could yield a similar mass spectrum. This is because the spectrum of DBP-A does not display a molecular ion peak, but rather peaks at m/z 107 and 109, which could arise from either loss of $\mathrm{CH}_{3}{ }^{\circ}$ from the proposed halohydrin $(\mathrm{M}=122 / 124)$ or loss of $\mathrm{NH}_{2} \mathrm{O}^{\bullet}$ from the aminoxy structure $(\mathrm{M}=139 / 141)$. In both scenarios, the elemental composition of the $\mathrm{m} / \mathrm{z} 107$ ion is expected to be $\mathrm{C}_{4} \mathrm{H}_{8} \mathrm{ClO}^{+}$, whose calculated mass (107.0258) matches the measured mass of Table 1.

The conclusion that DBP-A is a halohydrin, rather than an aminoxy compound, follows from the ammonia CI mass spectrum of Figure 2(d). The spectrum shows sizeable peaks at $\mathrm{m} / \mathrm{z} 140$ and 142, which at first glance could be ascribed to the $\left[\mathrm{M}+\mathrm{H}^{+}\right]$ions of the aminoxy compound. However, ammonia chemical ionization of secondary and tertiary alcohols may also lead to the formation of $\left[\mathrm{M}+\mathrm{NH}_{4}{ }^{+}\right]$adduct ions [14]. Therefore, the CI mass spectrum is also consistent with DBP-A having a molecular mass that matches that of the halohydrin 4-chloro-2-methylbutan-2-ol ( $\mathrm{M}=122 / 124)$.

The elemental compositions of the ammoniated halohydrin and the protonated aminoxy compound, that is, $\mathrm{C}_{5} \mathrm{H}_{15} \mathrm{NOCl}$ and $\mathrm{C}_{4} \mathrm{H}_{11} \mathrm{NO}_{2} \mathrm{Cl}$, respectively, differ in mass by $0.0358 \mathrm{Da}$. Therefore a mass spectrometer operating with a minimum resolution of 4000 could establish the elemental composition of DBP-A. An instrument capable of such accurate mass measurements was not available in the MOE laboratory at the time [5] appeared. This prompted us to reexamine the putative DBPs using the Micromass GCT (time-of-flight) instrument at McMaster University, which is capable of a maximum resolution of 5000 .

As shown in Table 2, the measured mass of 140.08465 is consistent with ammoniated halohydrin ion $\mathrm{C}_{5} \mathrm{H}_{15} \mathrm{NO}^{35} \mathrm{Cl}$ but not with the protonated aminoxy compound $\mathrm{C}_{4} \mathrm{H}_{11} \mathrm{NO}_{2}{ }^{35} \mathrm{Cl}$. The consecutive losses of $\mathrm{H}_{2} \mathrm{O}$ and $\mathrm{NH}_{3}$ from the $\mathrm{m} / \mathrm{z} 140$ ion account for the presence of the fairly intense $\mathrm{m} / \mathrm{z} 105$ peak in the CI mass spectrum. These results indicate that DBP-A is a halohydrin with a molecular mass of 122/124 and the elemental composition $\mathrm{C}_{5} \mathrm{H}_{11} \mathrm{OCl}$. 


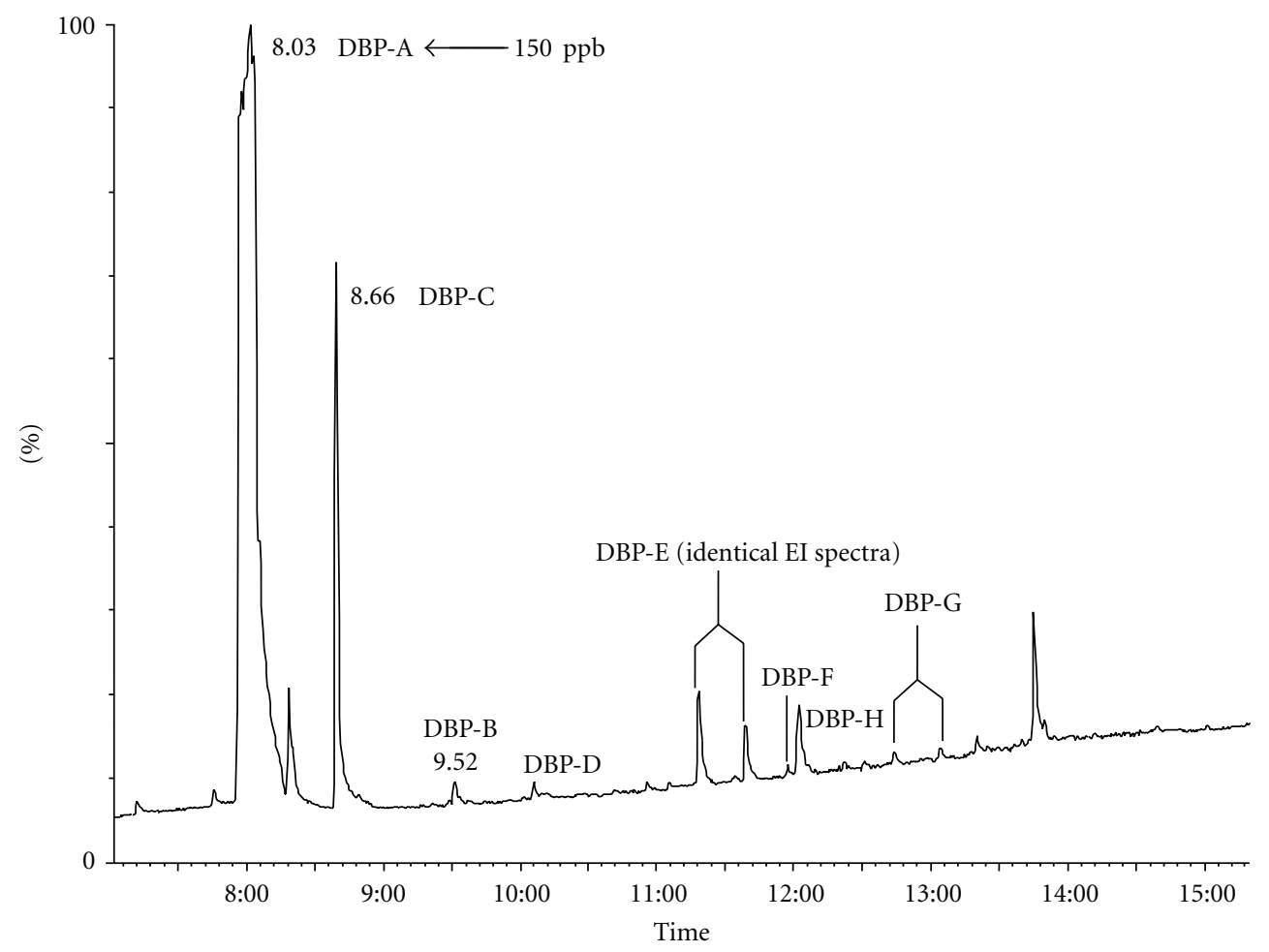

FIGURE 1: Total ion chromatogram (TIC) of a treated drinking water extract.

TABLE 2: Accurate mass measurements ( $\mathrm{NH}_{3} \mathrm{CI}$ mode) of the DBPs using GCT and FTICR instruments.

\begin{tabular}{|c|c|c|c|c|c|c|}
\hline DBP & Formula & Mass (calculated) & Mass $(\mathrm{GCT})^{[\mathrm{a}]}$ & Dev..$^{[c]}$ & Mass (FTICR) ${ }^{[\mathrm{b}]}$ & Dev. ${ }^{[c]}$ \\
\hline \multirow{4}{*}{ A } & $\mathrm{C}_{5} \mathrm{H}_{13} \mathrm{~N}^{35} \mathrm{Cl}$ & 122.07310 & 122.07355 & 3.7 & 122.07323 & 1.0 \\
\hline & $\mathrm{C}_{4} \mathrm{H}_{10} \mathrm{NO}_{2} \mathrm{Cl}$ & 140.04783 & 140.08465 & 263 & 140.08374 & \\
\hline & $\mathrm{C}_{5} \mathrm{H}_{15} \mathrm{NO}^{35} \mathrm{Cl}$ & 140.08367 & 140.08465 & 7.0 & 140.08374 & 0.5 \\
\hline & $\mathrm{C}_{5} \mathrm{H}_{15} \mathrm{NO}^{37} \mathrm{Cll}$ & 142.08072 & 142.08125 & 3.7 & 142.08079 & 0.5 \\
\hline \multirow{4}{*}{ B } & $\mathrm{C}_{5} \mathrm{H}_{13} \mathrm{~N}^{79} \mathrm{Br}$ & 166.02259 & 166.02425 & 10.0 & 166.02249 & 0.6 \\
\hline & $\mathrm{C}_{5} \mathrm{H}_{13} \mathrm{~N}^{81} \mathrm{Br}$ & 168.02054 & 168.02205 & 9.0 & 168.02041 & 0.8 \\
\hline & $\mathrm{C}_{5} \mathrm{H}_{15} \mathrm{NO}^{79} \mathrm{Br}$ & 184.03315 & - & - & 184.03311 & 0.2 \\
\hline & $\mathrm{C}_{5} \mathrm{H}_{15} \mathrm{NO}^{81} \mathrm{Br}$ & 186.03111 & - & 一 & 186.03102 & 0.4 \\
\hline \multirow{2}{*}{$\mathrm{C}$} & $\mathrm{C}_{5} \mathrm{H}_{15} \mathrm{NO}^{35} \mathrm{Cl}$ & 140.08367 & 140.08485 & 8.4 & 140.08367 & 0.0 \\
\hline & $\mathrm{C}_{5} \mathrm{H}_{15} \mathrm{NO}^{37} \mathrm{Cl}$ & 142.08072 & 142.08105 & 2.3 & 142.08081 & 0.6 \\
\hline
\end{tabular}

Note. Measurements obtained using ${ }^{[a]}$ treated drinking water samples; ${ }^{[b]}$ authentic standards of the halohydrins; ${ }^{[c]}$ the deviation from the calculated value is given in parts per million.

The EI mass spectrum of Figure 2(a) is very close to the database spectrum of 4-chloro-2-methylbutan-2-ol, whose molecular ion, $\left(\mathrm{CH}_{3}\right)_{2} \mathrm{C}(\mathrm{OH}) \mathrm{CH}_{2} \mathrm{CH}_{2} \mathrm{Cl}^{l^{+}}$, readily dissociates into protonated acetone $\mathrm{m} / \mathrm{z} 59$ ions, $\mathrm{CH}_{3} \mathrm{C}(\mathrm{OH}) \mathrm{CH}_{3}{ }^{+}$, by direct bond cleavage. The prominent $\mathrm{m} / \mathrm{z} 43$ peak undoubtedly represents the acetyl cation, $\mathrm{CH}_{3} \mathrm{C}=\mathrm{O}^{+}[15]$. Tandem mass spectrometry experiments [15] performed using the ZAB-R instrument [12] indicate that this ion is likely formed by the route depicted in Scheme 3 .

The other $\mathrm{C}_{5} \mathrm{H}_{11} \mathrm{OCl}$ isomer expected to show similar dissociation characteristics is the halohydrin 3-chloro-2methylbutan-2-ol of Scheme 2. It is also expected to dis- sociate into protonated acetone $(\mathrm{m} / \mathrm{z} 59)$ ions by direct bond cleavage. Indeed, our EI mass spectra of the two isomers appear to be very similar. However, the 3- and 4-chlorohydrins have very different retention times ( 8.03 versus 10.15 minutes), and this makes their differentiation by GC-MS quite easy. These results leave little doubt that DBP-A is 3chloro-2-methylbutan-2-ol.

The halohydrin 3-bromo-2-methylbutan-2-ol yields the best library match to the EI spectrum of DBP-B shown in Figure 2(b). Here too, an ammonia CI experiment, (see Table 2) confirms that we are dealing with a halohydrin rather than an aminoxy compound. Authentic samples of the 


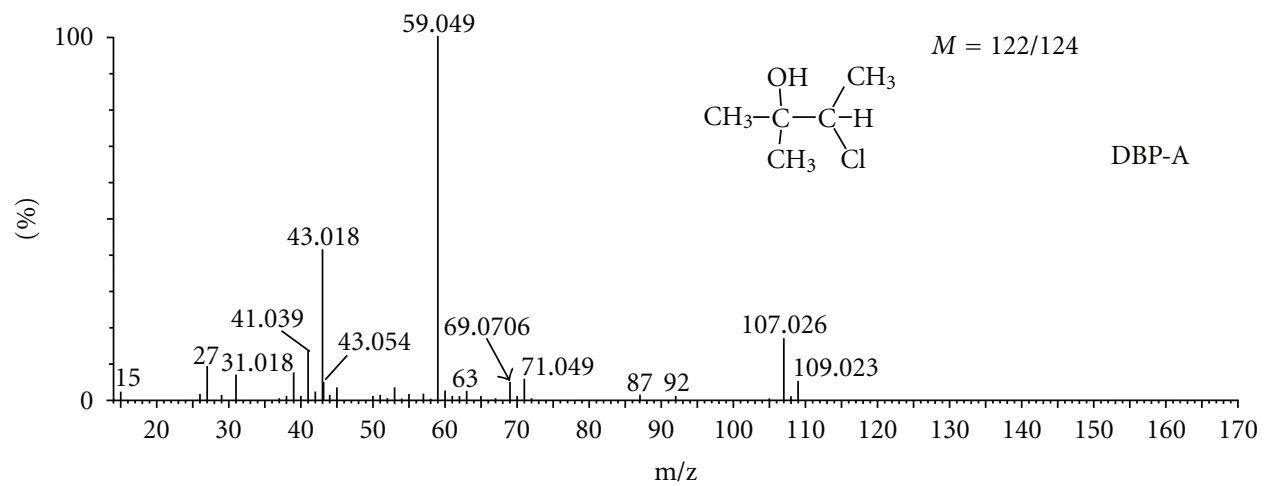

(a)

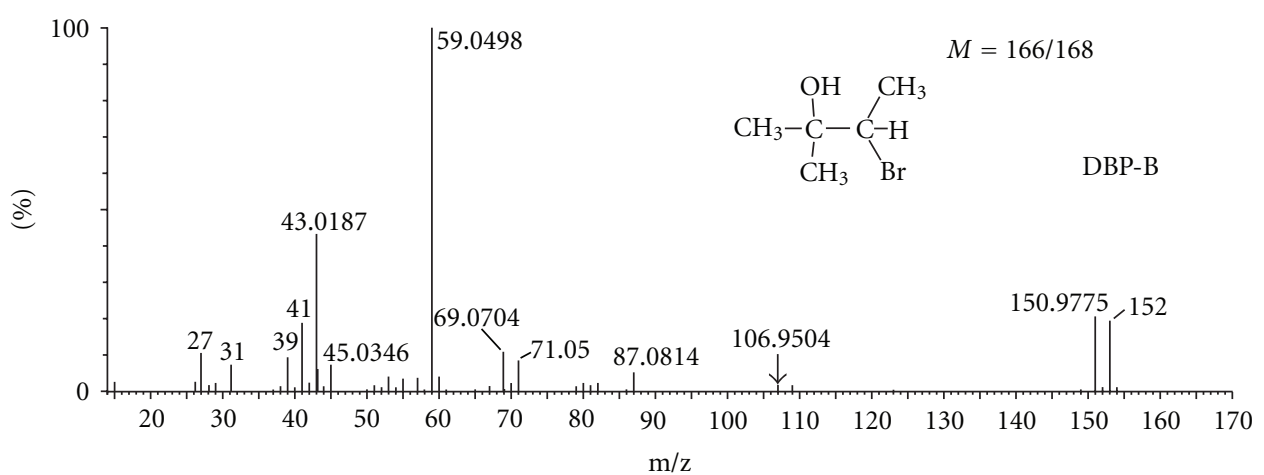

(b)

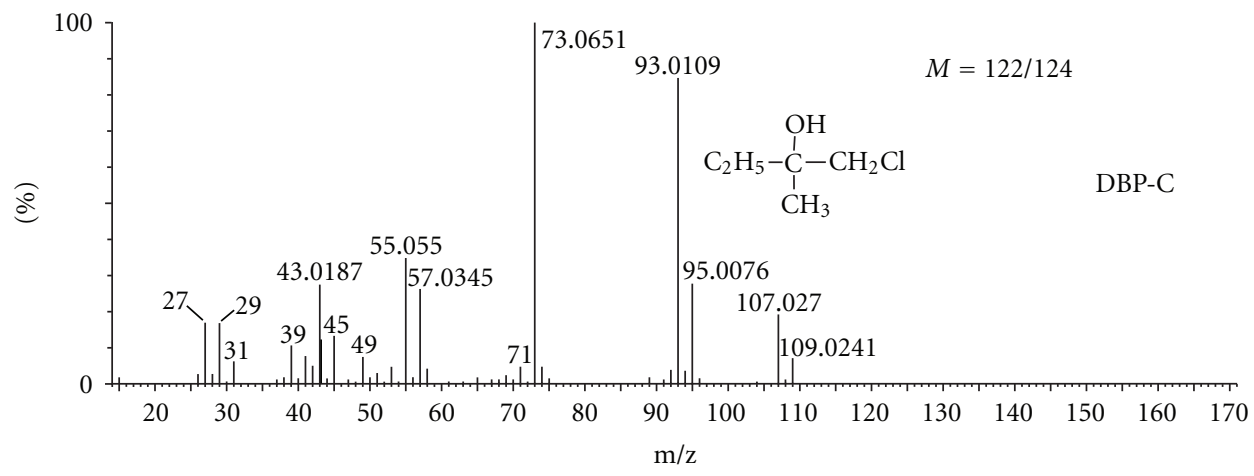

(c)

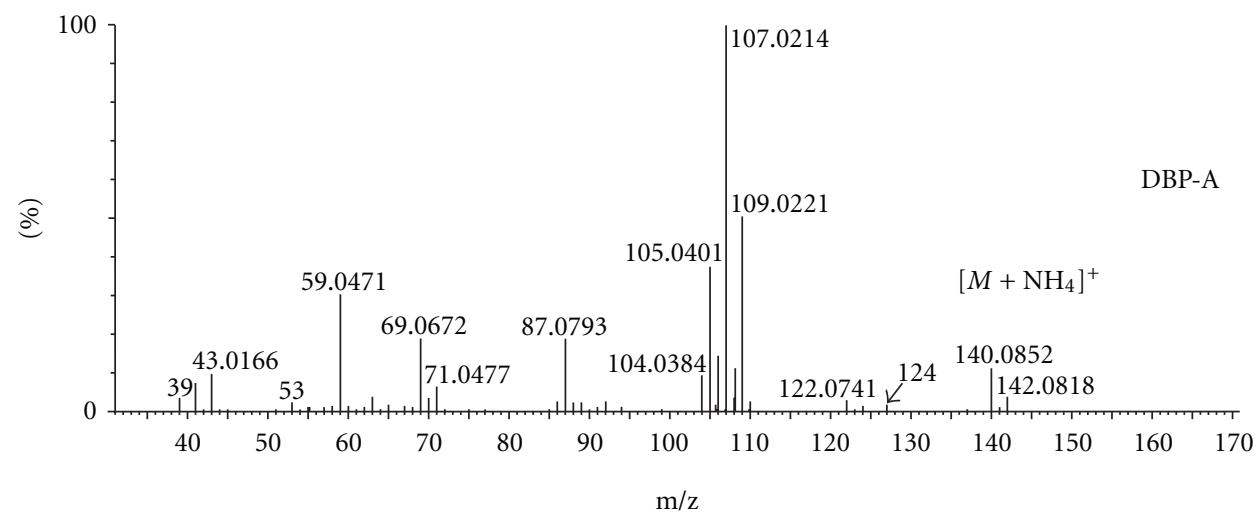

(d)

Figure 2: EI mass spectra of (a) DBP-A, (b) DBP-B, (c) DBP-C, and (d) the CI mass spectrum of DBP-A obtained on the Micromass GCT instrument. 


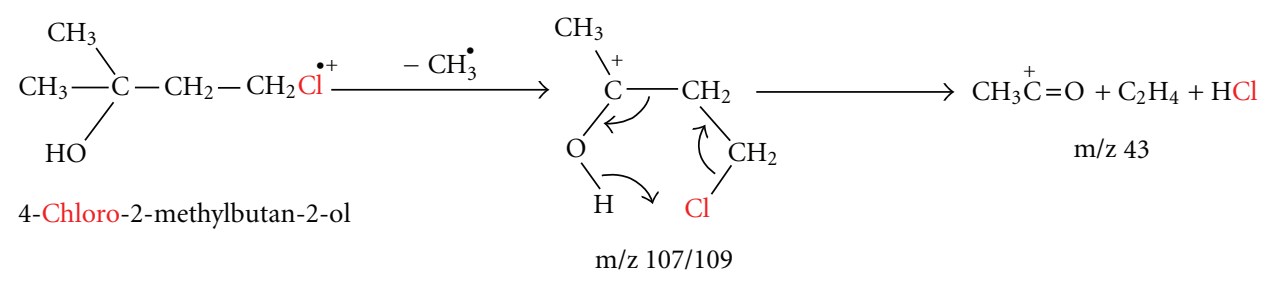

SCHEME 3

3- and 4-bromo-2-methylbutan-2-ol isomers were obtained and subjected to GC-MS analysis. From this analysis it follows that DBP-B is 3-bromo-2-methylbutan-2-ol.

The CI mass spectrum of DBP-C displays signals at $\mathrm{m} / \mathrm{z}$ 140 and 142. The accurate mass measurements of Table 2 indicate that these peaks represent the ammonium adduct $\left[\mathrm{M}+\mathrm{NH}_{4}\right]^{+}$of a halohydrin. Interpretation of the EI spectrum of DBP-C (Figure 2(c)) leads to 1-chloro-2-methylbutan-2-ol, an isomer of DBP-A: the ions at m/z 107/109 and $\mathrm{m} / \mathrm{z}$ 93/95 in the EI mass spectrum may result from the competing losses of $\mathrm{CH}_{3}{ }^{+}$and $\mathrm{C}_{2} \mathrm{H}_{5}{ }^{\bullet}$ from the molecular ion. The base peak at $\mathrm{m} / \mathrm{z} 73$ can readily be explained by the loss of $\mathrm{ClCH}_{2}$ from the molecular ion. This proposal is strongly supported by an experiment with an authentic sample of 1-chloro-2-methylbutan-2-ol, whose mass spectrum and retention time match those of DBP-C.

Recognizing the need for accurate mass measurements for the structure analysis of unknown compounds, the Ministry of the Environment has acquired a Fourier transform ion cyclotron resonance (FTICR) mass spectrometer capable of a mass resolution of 100,000 on the capillary GC time scale. Tables 1 and 2 show results for authentic standards of DBP-A, B, and C obtained using the FTICR instrument. It is seen that the results obtained from both the GCT and FTICR instruments are in excellent agreement.

3.2. The Halohydrins May Not be Genuine DBPs, but Rather Laboratory Artefacts. An important clue that the halohydrins reported in the study of [5] may not be genuine DBPs was the observation that the acid fraction of the liquid-liquid extraction procedure described in Section 2 contained the highest concentrations of these DBPs. This is contrary to the expectation that the halohydrins, which are not appreciably water soluble and neither acidic nor basic, would be more concentrated in the neutral fraction. Indeed, a small quantity $(\sim 0.1 \mathrm{mg})$ of the labelled halohydrin $\left(\mathrm{CD}_{3}\right)_{2} \mathrm{C}(\mathrm{OH}) \mathrm{CHClCH}_{3}$, spiked into an $800 \mathrm{~mL}$ water sample, is not detected in the acid fraction but rather in the combined base/neutral fraction. This result implies that the generation of the purported DBPs is promoted by acid conditions and occurs during the extraction procedure $[9,16]$.

As shown in Scheme 4, we propose that DBP-A is generated in the reaction of residual chlorine in the water sample (in the form of hypochlorous acid) with 2-methyl2-butene, which is used as the stabilizer of the $\mathrm{CH}_{2} \mathrm{Cl}_{2}$ used for extraction. The bromo analogue DBP-B may arise from a $\mathrm{Cl} / \mathrm{Br}$ exchange reaction of DBP-A with naturally occurring $\mathrm{Br}^{-}$ions in the water [9] or by oxidation of bromide to

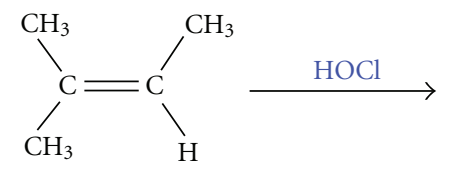

2-Methyl-2-butene

Stabilizer in methylene chloride

(used for extraction)

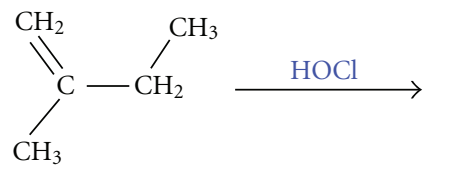

2-Methyl-1-butene<smiles>CC(Cl)C(C)(C)O</smiles>

DBP-A
Scheme 4: The halohydrins are generated in the reaction of residual chlorine in the water sample with the stabilizer (2-methyl-2-butene) of the $\mathrm{CH}_{2} \mathrm{Cl}_{2}$.

bromine by excess chlorine and subsequent reaction of bromine and water with 2-methyl-2-butene.

To support this proposal, a control experiment was performed with a stock solution of $\mathrm{CH}_{2} \mathrm{Cl}_{2}$ spiked with $50 \mathrm{ppm}$ of the labelled 2-methyl-2-butene $\left(\mathrm{CD}_{3}\right)_{2} \mathrm{C}=\mathrm{CHCH}_{3}$. Analysis of a water sample extracted with this spiked solvent indeed showed GC-MS signals of comparable intensity for labelled and unlabelled DBP-A as well as labelled and unlabelled DBP-B.

DBP-C is proposed to be generated from 2-methyl-1butene (see Scheme 4) which is likely to be a minor component in technical grade (>90\%) 2-methyl-2-butene: the dehydration of 2-methyl-2-butanol yields primarily 2-methyl-2-butene and its isomer 2-methyl-1-butene as a minor component [13].

A complementary experiment, in which 5 ppm of $\mathrm{NaOCl}$ was added to the water sample, showed a 100-fold increase in yield of the chlorohydrins DBP-A and DBP-C. In contrast, the yield of DBPs was reduced 100-fold when $200 \mathrm{ppm}$ of sodium thiosulfate was added to the treated drinking water sample to reduce any residual chlorine. This shows that the better part of the halohydrins in our samples are laboratory artefacts, but trace quantities may be genuine DBPs [9].

\section{Conclusions}

The present study leaves little doubt that DBP-A does not have the previously proposed "aminoxy" structure. It shows 
that DBP-A is the halohydrin 3-chloro-2-methylbutan-2-ol and that DBP-B is its bromo analogue. The EI mass spectra of the 3-chloro and 4-chloro-isomers and their bromo analogues are closely similar, but their retention times are very different. We propose that DBP-C is the isomeric halohydrin 1-chloro-2-methylbutan-2-ol. This study also shows that halohydrins are not necessarily genuine disinfection by-products. They can also be laboratory artefacts generated by the reaction of residual chlorine in the water with the 2-methyl2-butene, a stabilizer in the $\mathrm{CH}_{2} \mathrm{Cl}_{2}$ extraction solvent. The interference of these artefacts can be minimized by adding sodium thiosulfate to the aliquots of drinking-water that are being investigated in the monitoring and testing process.

\section{Acknowledgments}

J. K. Terlouw and K. J. Jobst gratefully acknowledge financial support from the Ontario Ministry of the Environment for the collaborative research described in this paper. The assistance of Miss V. H. Coulthard and Miss K. E. Mercer in preparing the labelled halohydrins and 2-methyl-2-butene is gratefully acknowledged.

\section{References}

[1] S. D. Richardson, "Disinfection by-products and other emerging contaminants in drinking water," Trends in Analytical Chemistry, vol. 22, no. 10, pp. 666-684, 2003.

[2] C. Zwiener and S. D. Richardson, "Analysis of disinfection by-products in drinking water by LC-MS and related MS techniques," Trends in Analytical Chemistry, vol. 24, no. 7, pp. 613-621, 2005.

[3] S. D. Richardson, "New disinfection by-product issues: emerging DBPs and alternative routes of exposure," Global Nest Journal, vol. 7, no. 1, pp. 43-60, 2005.

[4] S. D. Richardson, "Water analysis: emerging contaminants and current issues," Analytical Chemistry, vol. 81, no. 12, pp. 46454677, 2009.

[5] V. Y. Taguchi, "Structural elucidation of disinfection byproducts in treated drinking water," Rapid Communications in Mass Spectrometry, vol. 15, no. 7, pp. 455-461, 2001.

[6] F. W. McLafferty and F. Turecek, Interpretation of Mass Spectra, chapter 9, University Science Books, South Orange, NJ, USA, 4th edition, 1993.

[7] K. J. Jobst, P. J. A. Ruttink, and J. K. Terlouw, "The remarkable dissociation chemistry of 2-aminoxyethanol ions $\mathrm{NH}_{2} \mathrm{OCH}_{2} \mathrm{CH}_{2} \mathrm{OH}^{+}$studied by experiment and theory," International Journal of Mass Spectrometry, vol. 269, no. 3, pp. 165176, 2008.

[8] K. J. Jobst, S. Jogee, R. D. Bowen, and J. K. Terlouw, "A mechanistic study of the prominent loss of $\mathrm{H}_{2} \mathrm{O}$ from ionized 2-hydroxyaminoethanol," International Journal of Mass Spectrometry, vol. 306, no. 2-3, pp. 138-149, 2011.

[9] T. W. Collette, S. D. Richardson, and A. D. Thruston Jr., "Identification of bromohydrins in ozonated waters," Applied Spectroscopy, vol. 48, no. 10, pp. 1181-1192, 1994.

[10] J. E. Cavanagh, H. S. Weinberg, A. Gold et al., "Ozonation byproducts: identification of bromohydrins from the ozonation of natural waters with enhanced bromide levels," Environmental Science and Technology, vol. 26, no. 8, pp. 16581662, 1992.
[11] G. M. Bennett and W. G. Philip, "CCLIII.- the influence of structure on the solubilities of ethers. Part II. Some cyclic ethers," Journal of the Chemical Society, pp. 1937-1942, 1928.

[12] H. F. van Garderen, P. J. A. Ruttink, P. C. Burgers, G. A. McGibbon, and J. K. Terlouw, "Aspects of the $\mathrm{CH}_{5} \mathrm{~N}_{2}$ potential energy surface: ions $\mathrm{CH}_{3} \mathrm{NHNH}^{+}, \mathrm{CH}_{3} \mathrm{NNH}_{2}{ }^{+}$and $\mathrm{CH}_{2} \mathrm{NHNH}_{2}{ }^{+}$and radicals $\mathrm{CH}_{2} \mathrm{NHNH}_{2}$ studied by theory and experiment," International Journal of Mass Spectrometry and Ion Processes, vol. 121, no. 3, pp. 159-182, 1992.

[13] F. C. Whitmore, C.S. Rowland, S. N. Wrenn, and G. W. Kilmer, "The dehydration of alcohols. XIX. t-Amyl alcohol and the related dimethylneopentylcarbinol," Journal of the American Chemical Society, vol. 64, no. 12, pp. 2970-2972, 1942.

[14] J. B. Westmore and M. M. Alauddin, "Ammonia chemical ionization mass spectrometry," Mass Spectrometry Reviews, vol. 5, pp. 381-465, 1986.

[15] J. L. Holmes, C. Aubry, and P. M. Mayer, Assigning Structures to Ions in Mass Spectrometry, CRC Press, Boca Raton, Fla, USA, 2007.

[16] Y. Xie and D. A. Reckhow, "Formation of halogenated artifacts in brominated, chloraminated, and chlorinated solvents," Environmental Science and Technology, vol. 16, no. 7, pp. 13571360, 1994. 


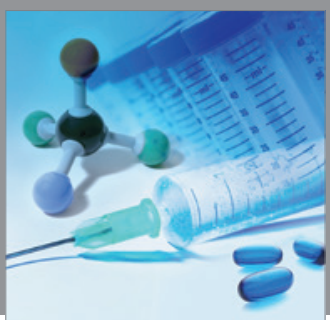

International Journal of

Medicinal Chemistry

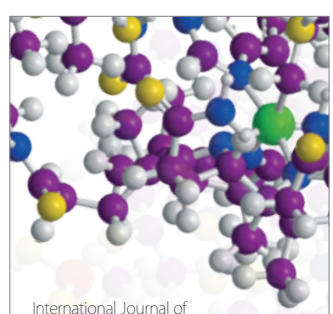

Carbohydrate Chemistry

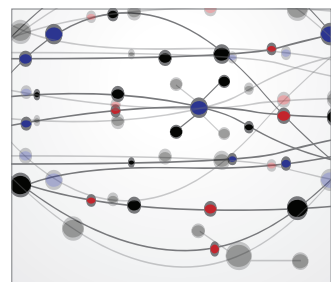

The Scientific World Journal
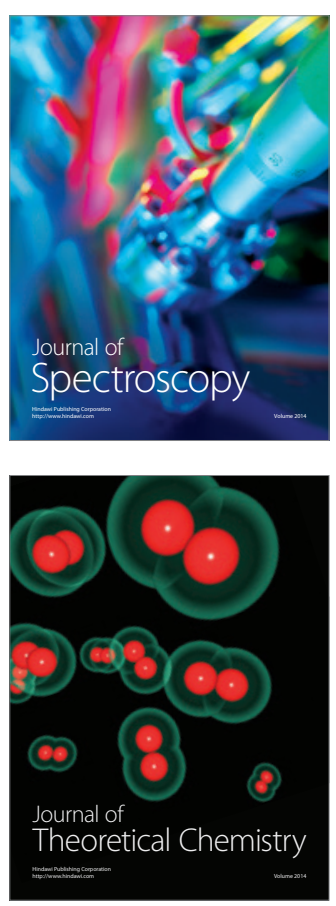
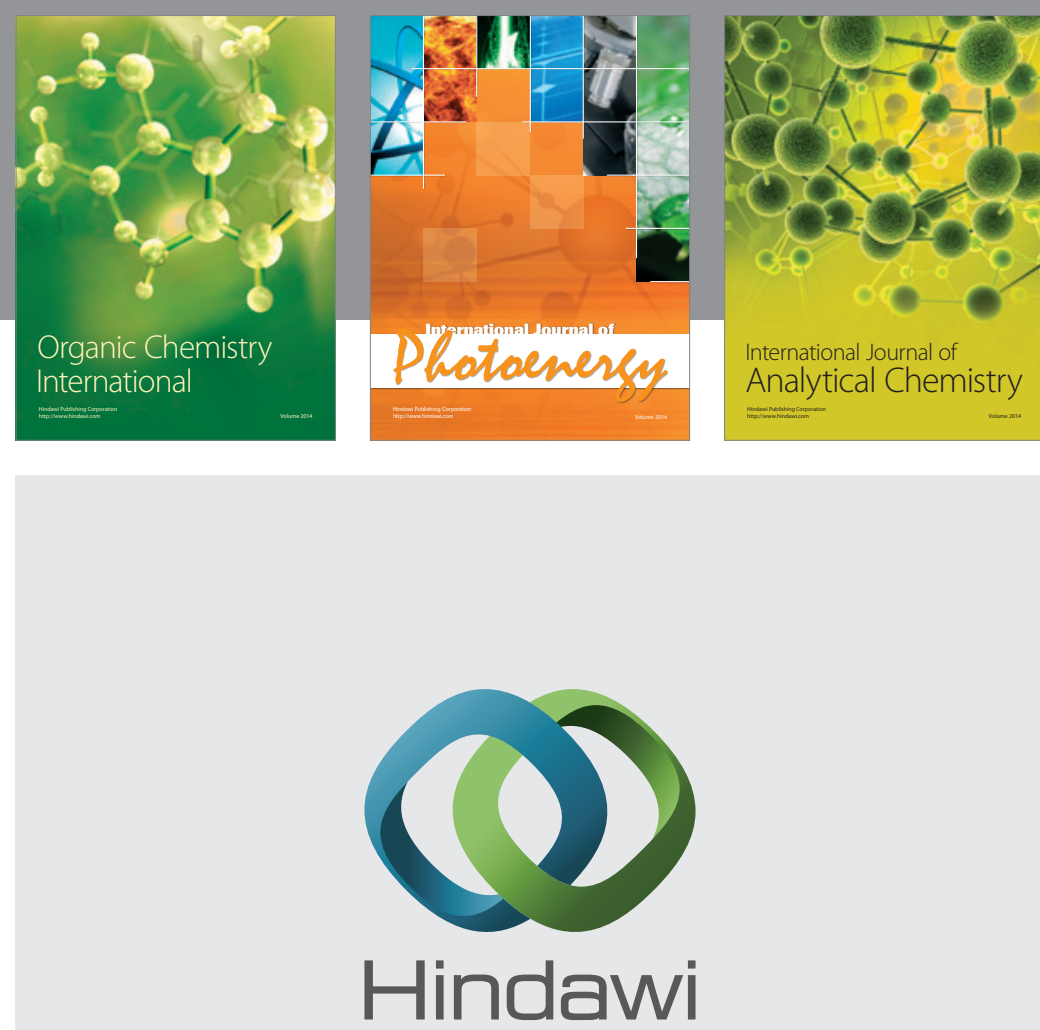

Submit your manuscripts at

http://www.hindawi.com
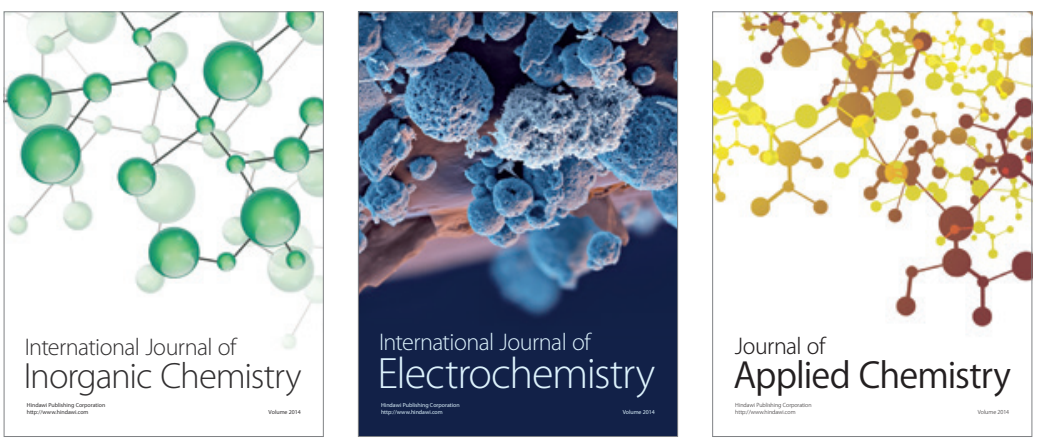

Journal of

Applied Chemistry
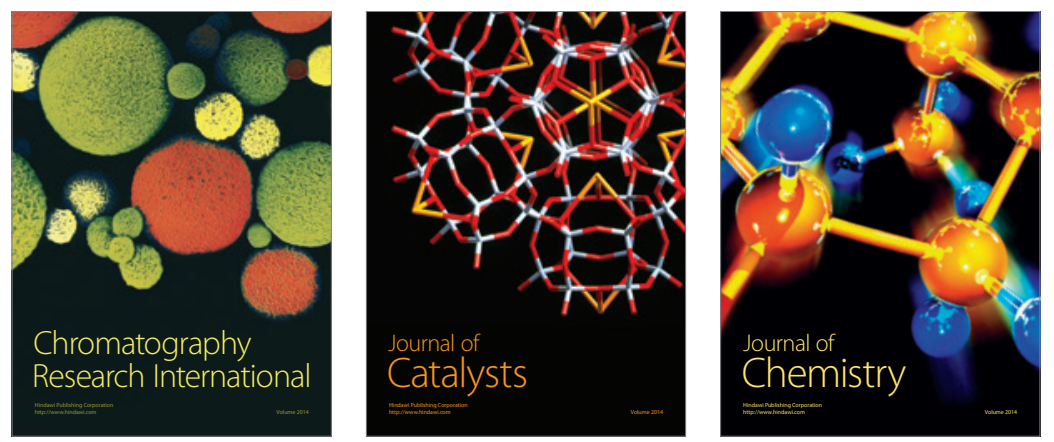
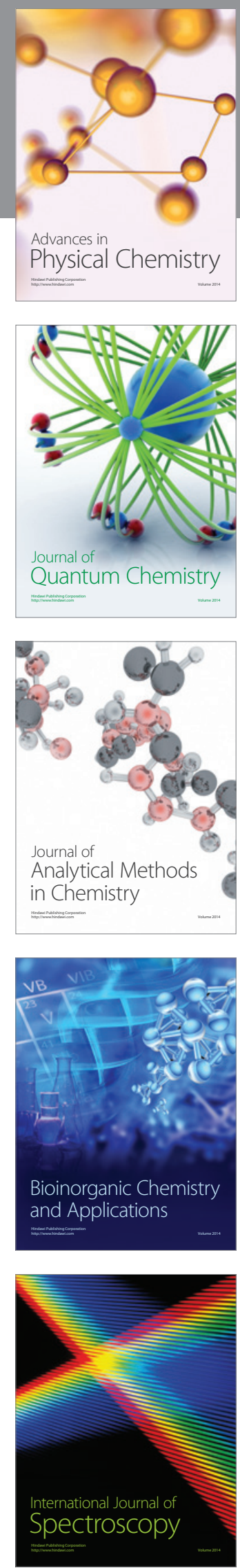